\title{
LA VALUOSA AJUDA, BÈL·LICA I DIPLOMÀTICA, PRESTADA AL COMTE DE BARCELONA, RAMON BERENGUER IV, PELS TORROJA, SENYORS DEL CASTELL DE SOLSONA
}

\section{Antoni Llorens i Solé}

\section{ELS TORROJA}

Tots els historiadors de Catalunya parlen dels Torroja. Uns més que altres estudien la influència que exerciren en les decisions polítiques i militars dels comtes de Barcelona Ramon Berenguer IV i Alfons el Cast, que els tingueren per consellers, i donen a conèixer la seva intervenció $i$ ajut en les conquestes de les places fortes de Tortosa i Lleida.

Tots parlen dels Torroja, però cap no diu que el seu llinatge radiqués a Solsona.

Les proves documentals de l'origen solsoni dels Torroja consten àmpliament en l'Arxiu Capitular de Solsona i ens han permès d'elaborar la genealogia que presentem. La tercera dedicació del temple de Santa Maria de la Canònica Agustiniana de Solsona, l'any 1163, fou una trobada familiar. El senyor del castell de Solsona, Ramon II de Torroja, acull el seu germà, Pere, bisbe de Saragossa, i el senyor oncle de tots dos, el bisbe de Barcelona, Guillem de Torroja, i tots els membres de la familia que hi acudiren, conjuntament amb el bisbe de la Seu d'Urgell, el consagrant, el de Pamplona, els comtes d'Urgell, els vescomtes de Cardona i tota la noblesa del país. 
La festa s'ho valia. El temple de la famosa Canònica havia estat acabat en la seva nau lateral dreta, en la qual hi treballaren els artistes vinguts de Tolosa de Llenguadoc: Gilabert i el seu taller, que va deixar-nos la seva obra mestra de la Mare de Déu del Claustre i Pere de Coma, de Besalú, que va construir la portada d'accés al claustre. La portada dels Fillols de la seu vella de Lleida en serà un complement j una ampliació quan, passat a la capital del Segrià, esdevindrà el seu arquitecte i el fundador de l'escola de Lleida.

L'apel-latiu «de Torroja», que Ecard Miró va escollir per al seu llinatge, ha eclipsat el denominatiu «de Solsona». És qüestió de noms, certament, però una qüestió que la història ha de posar en clar. També per causa de la unió de Catalunya i Aragó i del misteri pel qual Ramon Berenguer IV no volgué adoptar el títol de rei de Catalunya, els catalans hem estat tinguts per aragonesos. Qüestió de noms sense importància decisiva en la realitat, certament, però que no ens fa cap favor.

Heus aci la genalogia dels senyors del castell de Solsona. 


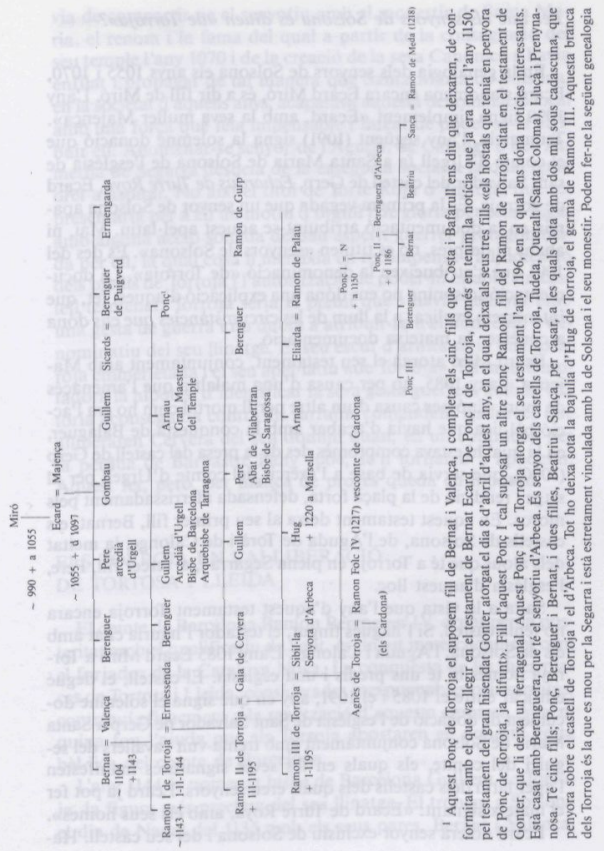


En la genalogia dels senyors de Solsona els anys 1055 i 1070 , Ecard s’anomena encara Ecard Miró, és a dir fill de Miró. L’any 1090 signa simplement «Ecard, amb la seva muller Majença». Tanmateix, l'any següent (1091) signa la solemne donació que el comte d'Urgell fa a Santa Maria de Solsona de l'església de sant Salvador del castell de Gerp, Echardus de Turre Roya, Ecard de Torroja. És la primera vegada que un senyor de Solsona apareix en la documentació atribuint-se aquest apel-latiu. Mai, ni abans ni després, no es titulen «senyors de Solsona». És des del 1091 que s’atribueixen la denominació «de Torroja». La documentació solsonina no ens dóna una explicació d'aquest fet, que intentarem explicar a la llum de les circumstàncies que ens dóna a conèixer la mateixa documentació.

Ecard Miró atorga el seu testament, conjuntament amb Majença, l'any 1085 , no per causa d'una malaltia que l'amenacés de mort, sinó per causa d'un altre perill mortal com ho era l'acció bèl-lica que havia d'acabar amb la conquesta de Balaguer, en la qual hi estava compromès des de la presa del castell de Gerp (1080), que servia de base a l'exèrcit del comte d'Urgell per al setge i rendició de la plaça forta, defensada aferrissadament pels moros. En aquest testament deixa al seu primer fill, Bernat, els castells de Solsona, de l'Aguda de Torà i de Calonge, la meitat dels alous que té a Torroja en plena Segarra i, al tercer fill, Pere, l'església d'aquest lloc.

Salta a la vista que l'any d'aquest testament Torroja encara no tenia castell. Si l'hagués tingut, el testador l'hauria citat amb els de Solsona, l'Aguda i Calonge. L'any 1085 Ecard Miró a Torroja només hi té uns predis i una església. El castell, el degué edificar entre el $1085 \mathrm{i}$ el 1091, any en què signa el solemne document de donació de l'església de Sant Salvador de Gerp a Santa Maria de Solsona conjuntament amb trenta-vuit cavallers del seguici del comte, els quals en les seves signatures manifesten l'apel-latiu dels castells dels quals eren senyors. Ecard ja pot fer el mateix signant: «Ecard de Turre Roya, amb els seus homes». Ecard no era senyor exclusiu de Solsona i del seu castell. Ha- 
via de compartir-ne el senyoriu amb el monestir de Santa $\mathrm{Ma}$ ria, el renom i la fama del qual a partir de la consagració del seu temple l'any $1070 \mathrm{i}$ de la creació de la seva Canònica s'havia enfilat i propagat de tal manera que Santa Maria de Solsona, en la societat d'aquells anys, acaparava aquesta denominació local amb una força que feia impensable l'intent de poder-se-la atribuir ell. Anomenar-se senyor de l'Aguda, de Calonge o de l'Atmetlla de Segarra desdeia de la categoria social a la qual tenia dret a aspirar. No així el títol de Torre Roja o Torroja, que representaria per a ell un motiu d'orgull i de glòria per estar lligat amb alguna acció sonada del seu esperit guerrer protagonitzada per ell, la qual cosa li mereixia en recompensa l'adjudicació dels predis de Torroja i l'autorització de poder-hi establir un castell termenat. Torroja seria el premi que s'havia guanyat amb una gesta de guerra i no dubtà a atribuir-se'n el nom com a denominatiu del seu llinatge. El seu escut d'armes seria una torre roja emmerletada i el seu apel-latiu «de Torroja». És molt temptadora la hipòtesi d'identificar la seva gesta guerrera amb la victòria aconseguida contra els sarraïns comandant les forces que alliberaren Cervera del seu domini quan, en un contracop per la pèrdua de Barbastre l'any 1064, se'n tornaren a apoderar. Aquest fet, però, per manca de proves queda en hipòtesi.

\section{ELS TORROJA EN LALLIBERACIÓ DE TORTOSA I LLEIDA}

El comte de Barcelona Ramon Berenguer IV, ornat per la posteritat amb el qualificatiu de Sant, és tingut merescudament com el forjador de la Cataluya Nova. La conquesta de les dues places de Tortosa i Lleida, considerades inexpugnables pels sarraïns, contribuí eficaçment a la realització d'aquesta empresa. Vegem quina fou l'ajuda que els Torroja aportaren en aquesta gesta bèl-lica del comte de Barcelona.

L'any 1144 és nomenat bisbe de Barcelona Guillem de Torroja, la figura més preclara del seu llinatge. El trobem a Solsona el dia de Nadal del 1135 amb els seus pares, Bernat i Valença, 
$i$ entre els dos germans, Berenguer i Arnau, signant conjuntament la donació d'un mas que tota la família fa a Santa Maria. Guillem afegeix en la seva signatura la dignitat que ostentava d'arcedià sense dir-nos de quina catedral, però, com que consta que era canonge de la d'Urgell, només podia ser-ho d'aquesta. Una segona trobada familiar a Solsona, la tenim amb motiu de la tercera dedicació del temple de Santa Maria, el novembre de 1163, essent bisbe de Barcelona, i trobant-s'hi amb els seus nebots, el senyor de Solsona, Ramon II de Torroja i Pere, bisbe de Saragossa. Del 1144 al 1171 és bisbe de Barcelona i, des d'aquest any, arquebisbe de Tarragona, on mor el 7 de maig de 1174.

Durant els cinc primers anys del seu bisbat es posa al costat de Ramon Berenguer IV en l'empresa de posar fi al domini sarrai a les terres catalanes. La mitra sembla que li ha desvetllat la vocació guerrera dels seus germans i avantpassats. Lany 1147 ajuda el comte en la campanya contra els moros d'Almeria, capital d'una taifa i refugi de pirates musulmans, presa el 17 d'octubre d'aquest any per les forces de Barcelona, Gènova i Pisa, que actuen sota el comandament de Ramon Berenguer IV i l'ataquen per mar mentre Alfons VII de Castella ho fa per terra. Es creu que Guillem de Torroja prengué part en la batalla personalment.

L'any següent (1148) és al setge de Tortosa amb les forces armades del Capítol de Barcelona. Trobant-se el comte mancat de diner per intentar la conquesta de la ciutat, extraordinàriament fortificada pels moros, Guillem posa a les seves mans els recursos necessaris. Tortosa cau el darrer dia d'aquest any. A més a més de Guillem de Torroja, trobem altres solsonins al setge de Tortosa: el paborde del seu monestir, Gauspert, amb els seus homes, i els canonges Ramon de Guspí i Ramon de Santjust. En un document consta que s' ha conservat en el seu trasllat el cartoral 1 de l'Arxiu Capitular, datat en el «setge de Tortosa" el dia 15 d'octubre del 1148, en el qual el comte de Barcelona fa l'ofrena d'un bon mas a Santa Maria de Solsona perquè el tingui amb totes les seves afrontacions i pertinences «quan la divina clemència lliuri a les seves mans aquesta ciutat». D'altra ban- 
da, Ramon II de Torroja, senyor de Solsona, nebot del bisbe de Barcelona, també hi era amb els seus homes, el qual fou donat en ostatge als genovesos que ajudaren en la conquesta de Tortosa, per respondre dels setze mil morabetins estipulats pel seu ajut. La seva condició de nebot del comte i del bisbe de Barcelona oferia garanties suficients per al cobrament del deute. Guillem de Torroja signa la carta de població de Tortosa, atorgada per Ramon Berenguer, i consagra el primer bisbe d'aquella seu, Gaufred, abat de Sant Ruf d'Avinyó, el dia 9 d'agost de 1151.

La caiguda de Tortosa desmoralitzà profundament els sarraïns. Els comtes de Barcelona i d'Urgell aprofiten l'ocasió i seguidament posen setge a la ciutat de Lleida, també molt fortificada, que es rendeix per capitulació el 24 d'octubre de 1149. No podia mancar-hi el bisbe Guillem de Torroja, que va acudir-hi amb forces armades per ell mateix, i que en recompensa va rebre cases $i$ béns de la ciutat rendida, els quals va lliurar al Capítol de Barcelona. Tampoc no hi mancaren els germans del bisbe Guillem, Berenguer i el Gran Maestre del Temple, Arnau de Torroja, amb altres guerrers del Solsonès.

A partir d'aquí acaba l'activitat militar de Guillem de Torroja i comença la seva activitat política i diplomàtica al costat del comte barceloní.

\section{ELS TORROJA I LA UNIÓ DE CATALUNYA I ARAGÓ}

En cenyir Guillem de Torroja la mitra de Barcelona, aquesta unió ja era un fet. El comte Ramon Berenguer IV ja era l'amo indiscutit d'Aragó. Amb una habilitat diplomàtica sorprenent havia anat lligant tots els caps en el complicat procés que menà a la confederació dels dos Estats. Roma, però, no havia donat cap bel-ligerància al rei monjo Ramir, ni en vida ni en mort, i per aquest motiu ignorava totes les conseqüències del seu regnat. La posició de la Santa Seu era que el testament del rei d'Aragó, Alfons el Bataller, germà del monjo Ramir, era vàlid $i$ vigent. En aquest testament el titular del regne, Alfons el Bataller, instituïa hereus els tres ordes de cavalleria: Sant Sepulcre, Hos- 
pital i Templers. En conseqủència, el regne d'Aragó passava, per parts iguals, a aquests tres ordes. La cúria de Roma havia de defensar aquest heretatge i no sabia res d'un monjo que tenia una filla, Peronella, promesa pel seu pare en matrimoni al comte de Barcelona quan encara era un infant. En virtut d'aquest prometatge el comte de Barcelona esdevenia rei d'Aragó. Des del punt de vista de Roma, escriuen historiadors insignes, Aragó havia estat, de moment, esborrat per mitjà del testament del Bataller, que l'havia dividit en tres parts iguals llegades al tres ordes esmentats. Lúnica solució legal del conflicte era la cessió per part dels tres ordes del seu heretatge al comte de Barcelona. Els dos primers, del Sepulcre i de l'Hospital, ho feren per un conveni amb el comte, i el dels Templers, en virtut d'un acord especial, l'any 1143, al qual assisti el legat pontifici, cardenal Guido, acord que afavoria molt els Templers per les concessions que el comte els féu.

En aquest context històric es produeix el nomenament per part de la mitra de Saragossa de Pere Torroja, nebot del bisbe de Barcelona, Guillem. Això ens fa suposar que la seva mà era la que ho movia tot. Va aconseguir que Ramon Berenguer IV fos reconegut per Roma no solament com a comte de Barcelona i marquès de Provença com fins aleshores havia fet, sinó també com a Príncep d'Aragó, que havia rebut de mans dels hereus del Bataller el govern suprem del pais com a successor immediat seu. La cúria de Roma no dóna cap bel-ligerància al rei monjo Ramir, ni després de la seva mort, i per això no existien per ella les conseqüències del seu regnat. Calia assegurar, a més, que a la frontera no es produís una hegemonia eclesiàstica de Castella que reforcés la seva possible hegemonia política. Això ho aconsegui la Santa Seu decretant que les fronteres polítiques establertes entre Castella i Aragó valguessin també per a la divisió eclesiàstica. Efectivament, l'any 1154, és a dir dos anys després de l'entronització de Pere Torroja a la seu de Saragossa, aquest bisbat va quedar subordinat a l'arquebisbat de Tarragona. Anastasi IV va decidir aquest any els bisbats que n'havien de dependre. L'arquebisbat de Tarragona comprenia geogràficament tot l'àmbit que Ramon Berenguer IV dominava com a comte de Barcelona 
i com a Príncep d'Aragó. L'episcopologi de Saragossa relleva com un mèrit del bisbe Pere de Torroja el fet d'haver aconseguit del papa la delimitació de la diòcesi, que tants conflictes havia suscitat $\mathrm{i}$ podia suscitar encara.

Ramon Berenguer IV va morir el 1162. Havia instituit hereu el seu fill, Ramon. Peronella, però, reina d'Aragó, que el va sobreviure fins al 1173, en fer donació dels seus Estats en el testament diu que els deixa «al meu fill Alfons, rei d'Aragó i comte de Barcelona, el qual en el testament del meu marit és anomenat Ramon". Un dels marmessors de Peronella és el bisbe Guillem, el qual, amb els altres dignataris de la cort del comte, s'avé a aquest canvi de nom del futur rei Alfons el Cast. Alguns historiadors, com Rovira i Virgili, Soldevila i altres, hi veuen una imposició aragonesa, mente que Kehr, Cabestany i alguns més, acceptant la teoria legitimista, ho atribueixen a una voluntat de continuar la dinastia d'Alfons el Bataller. Per al marmessor, Guillem de Torroja representaria una solució política de cara a Roma.

Guillem de Torroja fou nomenat, conjuntament amb Guillem de Montcada, conseller del futur rei Alfons el Cast, que tot just tenia cinc anys quan va morir el seu pare, d'acord amb les darreres investigacions. De fet, n'esdevingueren tutors fins a la seva majoria d'edat, proclamada l'any 1177 quan tenia setze anys. Durant tots aquests anys Guillem té el govern amb el Montcada, Gran Senescal de la Confederació Catalano-Aragonesa, i amb la seva actuació política confirmen i promouen la pau i unió entre els dos Estats.

L'any 1171 Guillem és promogut a l'arquebisbat de Tarragona. El seu antecessor havia estat assassinat pel potent «Príncep de Tarragonan, Robert, que es trobava en la necessitat de pacificar l'ambient creat per la violència sorgida amb motiu de les disputes que el «Príncep» provocava contra l'arquebisbe. També el seu successor fou assassinat. D'acord amb el comte-rei, acabà de precisar la delímítació civil i eclesiástica de l'arxidiòcesi, i mori a Tarragona l'any 1174.

Aquest fill preclar de Solsona esdevingué la primera autoritat eclesiàstica de la Corona d'Aragó i tingué un protagonisme, reconegut per la Santa Seu, en la història de Catalunya del seu 
temps. El doble esperit dels Torroja, heretat dels seus pares, guerrer i de profunda religiositat, es fa manifest en ell com també es manifestarà en els seus germans Berenguer i Arnau. Esperit de religiositat i de pau que contrasta amb l'ambient de violència, d'assassinats, de relaxament de costums i d'heretgies que es respirava per tot Europa i més especialment a la zona pirinenca, i esperit guerrer en la defensa dels Llocs Sants i en la lluita contra la mitja lluna, en la qual el seu germà Arnau tindrà un lloc destacat i decisiu. Tots els Torroja es manifesten protectors decidits de la reforma eclesiàstica preconitzada pel papa Gregori VII, per mitjà de la Congregació Agustiniana de Sant Ruf d'Avinyó, de la qual la Canònica de Solsona n'era un centre actiu dels més rellevants, i al mateix temps de l'ordre del Temple, prestant ajut al Gran Mestre Arnau, mort a Verona en un viatge per cercar suport i guerrers a França i a Anglaterra l'any 1185.

\section{L'AJUT PRESTAT A SARDENYA}

La vinculació dels Torroja de Solsona amb els comtes de Barcelona s'accentua i esdevé personal amb el nebot del bisbe Guillem, Ramon II de Torroja, que hem vist servir d'ostatge als genovesos per cobrar el deute convingut per la seva participació en la presa de la plaça forta de Tortosa.

És la figura més rellevant de la tercera generació del seu gloriós llinatge. El 1147 es casa amb Gaia de Cervera, la darrera filla de Ponç i d'Almodis, germana de Ramon Berenguer IV, raptada per Ponç al mateix palau barceloní del comte i dipositada a Castellfollit de Riubregós. Després de fetes les paus amb el comte barceloni, segui el matrimoni.

És un dels testimonis del testament sagramental de Ramon Berenguer IV del 1162.

Entre les seves activitats al servei de la política del comte cal remarcar la seva intervenció en el conflicte suscitat per la successió del jutjat d'Arborea, càrrec equivalent al de príncep de Sardenya. El 1181 es desplaça a l'illa amb la seva muller per salvaguardar els drets al principat de la seva cunyada Agalbursa, 
germana de Gaia, la qual els reservava per al seu nebot, Hug Ponç de Cervera o Poncet de Bas, de qui Ramon era oncle i tutor. Els disputava el fillastre d'Agalbursa, Pere, mentre genovesos i pisans s'immiscien en la disputa interessats en els dos bàndols contraris. Davant la complexitat del conflicte i preveient la repercussió que la seva solució podia tenir per a Catalunya, Ramon suggereix a Alfons el Cast, cosí de Gaia i d'Agalbursa, una intervenció armada. Un cos d'exèrcit, integrat per rossellonesos sota el comandament del comte de Foix, és enviat a Sardenya. El conflicte acaba amb el tractat d'Oristany (1192), en el qual el pretendent Pere reconeix a favor d'Hug, el nebot i hereu d'Agalbursa, el domini sobre la meitat del jutjat d'Arborea, que exerciria sota la tutoria del seu oncle, Ramon de Torroja, el qual acceptà la clàusula que obligava Hug a residir a Sardenya. Aquesta fórmula de partició del principat de l'illa en dues parts no era nova. Gènova i Pisa ja se l'havien partit antigament per explotar la matèria primera que l'illa subministrava a les seves indústries. D'aquesta manera, el senyor del castell de Solsona amb la seva habilitat diplomàtica aconseguia que Catalunya posés el peu per primera vegada a Sardenya. 